\title{
Glucocorticoid-Induced Skin Atrophy: The Old and the New
}

This article was published in the following Dove Press journal:

Clinical, Cosmetic and Investigational Dermatology

\author{
Elena Niculet (iD) \\ Carmen Bobeica $\mathbb{D}^{2}$ \\ Alin L Tatu (D) ${ }^{3-5}$ \\ 'Department of Morphological and \\ Functional Sciences, Faculty of Medicine \\ and Pharmacy, "Dunarea de Jos" \\ University, Galati, Romania; ${ }^{2}$ Department \\ of Dermato-Venereology, Doctoral \\ School, University of Medicine and \\ Pharmacy “Gr. T. Popa”, lași, Romania; \\ ${ }^{3}$ Clinical Department, Faculty of Medicine \\ and Pharmacy, "Dunarea de Jos" \\ University, Galati, Romania; ${ }^{4}$ Research \\ Center in the Field of Medical and \\ Pharmaceutical Sciences, ReFORM-UDJ, \\ Galati, Romania; ${ }^{5}$ Dermatology \\ Department, "Sf. Cuvioasa Parascheva" \\ Clinical Hospital of Infectious Diseases, \\ Galati, Romania
}

\begin{abstract}
Glucocorticoids are major therapeutic agents highly used in the medical field. Topical glucocorticoids have biologic activities which make them useful in dermatology anti-inflammatory, vasoconstrictive, immune suppressive and antiproliferative, in treating inflammatory skin disorders (allergic contact eczema, atopic hand eczema, nummular eczema, psoriasis vulgaris or toxic-irritative eczema). Unfortunately, the beneficial effects of topical glucocorticoids are shadowed by their potential for adverse effects - muscle or skin atrophy, striae distensae, rubeosis or acne. Skin atrophy is one of the most prevalent side-effects, with changes found in all skin compartments - marked hypoplasia, elasticity loss with tearing, increased fragility, telangiectasia, bruising, cutaneous transparency, or a dysfunctional skin barrier. The structure and function of the epidermis is altered even in the short-term topical glucocorticoid treatment; it affects stratum corneum components, subsequently affecting skin barrier integrity. The dermis is altered by directly inhibiting fibroblast proliferation, reducing mast cell numbers, and loss of support; there is depletion of mucopolysaccharides, elastin fibers, matrix metalloproteases and inhibition of collagen synthesis. Atrophogenic changes can be found also in hair follicles, sebaceous glands or dermal adipose tissue. Attention should be paid to topical glucocorticoid treatment prescription, to the beneficial/adverse effects ratio of the chosen agent, and studies should be oriented on the development of newer, innovative targeted (gene or receptor) therapies.
\end{abstract}

Keywords: glucocorticoids, atrophy, skin, side-effects

\section{Introduction}

Glucocorticoids (GC) are one of the most important and highly used antiinflammatory agents, not only in the dermatological field, but also in rheumatology or allergology. They have a fast action onset and a cost profile which is favorable for the patient. GC are a class of steroid hormones, lipophilic, able to diffuse through the cell membrane, discovered in the 1940s as adrenal cortex extracts. Since then (the BC/before cortisol era as some authors part the history of medicine), they are used on a large scale, with important side-effects. ${ }^{1-4}$

GC are very important metabolic hormones as they determine an increase in fuel substrates by mobilizing aminoacids, glucose and free fatty acids from the body's deposits. They are catabolic hormones in nature, with decreasing effects on the overall body mass (including muscle mass). Concerning adipose tissue, GC have conflicting activities, being able to increase the de novo lipid producing (antilipolytic effect) and also exerting lipolytic activities through increases in lipaseexpression. ${ }^{5,6}$
Correspondence: Carmen Bobeica Department of Dermato-Venereology, Doctoral School, University of Medicine and Pharmacy "Gr. T. Popa", I6th University Street, lași 700 I I5, Romania Tel +40744368150

Email carmenbobeica I@gmail.com
Clinical, Cosmetic and Investigational Dermatology 2020:13 104|-1050

$104 \mid$

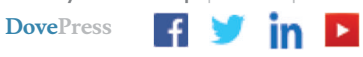

http://doi.org/|0.2147/CCID.S22421/ 
Immune suppression and anti-inflammatory activities are two important properties of GC which make them useful in treating skin disorders (such as systemic lupus erythematosus, occupational skin diseases), rheumatoid arthritis, inflammatory bowel disease (ulcerative colitis), asthma, transplant rejection, age-related macular degeneration, multiple sclerosis, sarcoidosis, nephrotic syndrome or even lichen sclerosus (which is a sclerosing, atrophic disease with an inflammatory component). ${ }^{1,2,7-11}$

Considering the type of treatment administered (long or short term, local or systemic), GC can induce GC resistance and have many side-effects such as - increased infection risk, hyperglycemia/increased insulin resistance/ diabetes, osteoporosis, osteonecrosis, obesity, infection, hypertension, impaired wound healing, mental disturbances (mood disorders such as depression), or skin atrophy (which will be discussed in further detail). ${ }^{1,2}$

\section{Materials and Methods}

For this narrative-type of review the following databases were searched (starting from 1992 and up until now) ScienceDirect Freedom Collection, Elsevier, SpringerLink Journals and PubMed, with the MeSH terms "glucocorticoid", "skin" and "atrophy" used alone or in combination. The articles that were not related to skin or skin atrophy were discarded according to their suitability to this review.

\section{Results and Discussions Topical GC}

$\mathrm{GC}$ and their efficacy or adverse effects depend on their potency. Concerning the topical GC, they have been ranked with the help of the skin blanching assay. Topical GC from the same class have comparable efficacy and potential for side effects.

Low-potency GC are recommended for long-term administration, while the high-potency ones are reserved for short-term treatment and for sites such as the palms and soles (here, the low-potency ones are ineffective).

The National Psoriasis Foundation classifies topical GC by potency into seven classes (I to VII): class I - superpotent (Clobetasol propionate), class II - potent (desoximetasone), class III - upper-mid strength (amcinonide), class IV - midstrength (flurandrenolide), class V - lower-mid strength (fluticasone propionate), class VI - mild (betamethasone valerate) and class VII - least potent (hydrocortisone).

An important factor in pharmacological response is the vehicle and the concentration of the drug in the vehicle (creams, ointments, lotions, gels, foams), a fact demonstrated by the dose-response curve in studies done with the same concentration topical GC, but with different vehicles. The vehicle is important in penetrating the stratum corneum, more specifically in the potency and bioavailability of the drug.

Ointments are generally considered to be more potent, as they have an occlusive effect which increases hydration and drug transportation. Creams do not exhibit this effect. Ointments are recommended in lichenified lesions, while creams are used in acute or subacute dermatoses. Foams (which register higher patient compliance), gels and lotions are better suited for scalp psoriasis. ${ }^{7,12}$

The adverse effects manifested in topical GC use also depend on the chemical structure of the therapeutic agent, as those with higher potency have a higher potential of producing side-effects such as skin atrophy. ${ }^{13}$

\section{The GC Receptor (GR)}

$\mathrm{GC}$ exert their actions by binding to their receptors - type I (mineralocorticoid receptor - MR) and type II (glucocorticoid receptor - GR), both intracellular nuclear receptors, transcription factors able to regulate gene expression. The GR, of which more is known, is a type of liganddependent nuclear receptor (part of the nuclear receptor superfamily), which is encoded by the NR3C1 gene. Some (non-genomic) GC actions have been found to be mediated with the help of a membrane-bound receptor (in the absence of a ligand). ${ }^{1,2,8,9,14,15}$ Only the unbound or free forms of GC have the capacity to interact with GR and exert their action.

GR are found throughout the body in multiple organ systems, such as: the epidermal and nervous systems, respiratory and reproductive systems, or the visual system, influencing numerous target genes. ${ }^{1,2,8,14} \mathrm{GCs}$ are involved in various processes, playing a fundamental role in cell proliferation, development, homeostasis, metabolism, mental health, reproduction, inflammation, immune responses (including allergy), or even cognitive processes. GR can have various polymorphisms. Some of them have been deemed positive (a reduced GC sensitivity - having a healthier, better metabolic profile) and other negative (an elevated GC sensitivity with an increased cardiovascular risk).

In the skin, the ubiquitous GR are found in higher levels in keratinocytes and fibroblasts, located in the epidermis and, respectively, the dermis. Keratinocytes from the epidermis and hair follicles have a high susceptibility for regulation by nuclear receptors. ${ }^{1,2,8,14,16}$ It seems that 
GR transactivation (a type of GR gene regulation) plays a major role in the atrophogenic effect that GC have on the skin. $^{17}$

GC can also bind to MR found in sweat gland ducts, sebaceous glands, hair follicles or the epidermis (with higher levels in undifferentiated keratinocytes). It is another member of the nuclear receptor superfamily, co-expressed in keratinocytes - along with GR, and it opens the door for other potential receptor-blocking treatment strategies (MR antagonists), which can also be applied topically in skin diseases. Further research needs to be done in order to establish which cellular processes are under the influence of which of the nuclear receptors (or possibly under both of these receptors); this could lead to the designing of targeted therapies with important anti-inflammatory activities and avoidance of skin deterioration. ${ }^{18-20}$

\section{The Skin Barrier}

The skin, the largest organ of the human body, is the first line of defense against potential harmful agents, acting as a barrier between the external and internal environments. It offers mechanical protection, has thermoregulatory properties and protects against water and electrolyte loss.

The structure of the skin consists of three layers - the epidermis, dermis and hypodermis (or subcutaneous cellular tissue). The epidermis is an avascular, multilayered squamous cell tissue which is made up of keratinocytes (or squamous cells) found in various maturation stages, with melanocytes, Merkel cells and Langerhans cells. The keratinocytes range from basal, metabolically active/proliferative cells, to superficial, non-functional, fully keratinized cells (dead keratinocytes/corneocytes) which form the stratum corneum. The corneocytes are terminally differentiated cells with a degraded nucleus, no DNA, which form a protective cornified envelope with an extracellular matrix high in neutral lipids. ${ }^{12,21}$

The dermis (superficial and deep) has a complex architecture with collagen and elastin fibers, blood vessels, nerve fibers and adnexal structures such as hair follicles, sweat and sebaceous glands. Fibroblasts, which are found in the dermis, play essential roles in inflammatory and immune responses; they also have surface GR, macromolecules which are also found on keratinocytes. The epidermis depends on the dermis from which it receives nutrients and oxygen through a process called diffusion. The hypodermis consists of adipose and muscle tissue. It mainly acts as a thermal regulator, energy deposit and has shockabsorbing properties. ${ }^{12}$

\section{GC and the Skin}

GC are key regulators in skin, being involved in inflammatory and metabolic processes, proliferation and differentiation.

Studies have shown that skin cells have the capacity for steroidogenesis (including GC) starting from cholesterol, due to the genes expressed that are involved in $\mathrm{GC}$ biosynthesis. $^{22,23}$ The equilibrium of GC levels is maintained in healthy skin with the help of two specialized enzymes called $11 \beta$-hydroxysteroid dehydrogenase 1 and 2 (11 $\beta$-HSD-1 and 11 $\beta$-HSD-2), two isoforms of the reductase $11 \beta$-hydroxysteroid dehydrogenase (11 $\beta$ HSD). The first isoform is expressed by keratinocytes in the epidermis and by fibroblasts in the dermis, while the second isoform is found in sweat glands. These enzymes catalyze the activation and respectively, inactivation, of extra-adrenal inactive GC, into active and respectively, inactive hormones, with further involvement in processes like inflammation, proliferation, healing and ageing. 11 $\beta$-HSD-1 was found to modulate inflammation, with higher levels in the elderly and obese; it has negative effects by suppressing cell proliferation and wound healing, with involvement in diseases such as psoriasis, basal and squamous cell carcinomas. $^{9,24-26}$

Considering the skin structure, topical GC treatment acts on all layers, but in order to reach the target cells, it needs to pass the stratum corneum with its lipid lamellae. This superficial layer of the epidermis acts as a barrier for substance absorption - it is made up of corneocytes/fully maturated keratinocytes with corneodesmosomes and lipids in between. These lipids with lamellar configuration, which are about $10 \%$ of the stratum corneum mass, consist of ceramides, cholesterol, fatty acids, triglycerides and cholesterol sulfate; they regulate the percutaneous absorption process and are synthetized by the lamellar bodies found in the superior viable epidermal layers. ${ }^{12,21}$

Percutaneous absorption is highly complex - it can be influenced by many factors such as the type of topical drug with its characteristics, bioavailability and vehicle, and the physiological state of the skin. In order for the topical GC to reach and act on the target cells, it needs to: release the GC from the formula, pass the stratum corneum barrier, partition into the epidermis and dermis, diffuse in order to reach the GR and to be able to bind to these receptors. ${ }^{12}$

As stated previously, GC are an important part of patient treatment in dermatology, topical administration 
being preferred partly due to its easy administration and easy patient acceptance, and partly due to four main important activities of GC - anti-inflammatory, vasoconstrictive, immune suppressive and antiproliferative. The latter make these agents useful in treating inflammatory skin disorders such as allergic contact eczema, atopic hand eczema, nummular eczema, psoriasis vulgaris or toxicirritative eczema. $^{7,12,27}$

Unfortunately, as in the case of other unsupervised or irresponsible drug use, the long-term/chronic use of GC in dermatology has serious (permanent) side-effects, mainly of metabolic and atrophic nature, such as - osteonecrosis, Cushing syndrome, hypertension, corticodependence, tachyphylaxis, exacerbation of diabetes, skin atrophy (also found with the use of mometasone furoate), contact dermatitis, rosaceiform dermatitis, striae distensae, rubeosis, telangiectasia, purpura, stellate pseudoscars, ulceration, infections (secondary demodicosis), hypo- or hyperpigmentation, hirsutism or acne. Disease exacerbation can also take place when using other drugs in dermatology or other medical fields, such as beta-blockers or statins and hydrochlorothiazide. One of the most important systemic side-effect in topical GC treatment in children (who are more susceptible to the adverse effects of topical GC) is suppression of the pituitary-adrenal axis, which could result in growth retardation. This is valid even for prior GC therapy, the adverse-effects risk being persistent (especially for systemic GC treatment). ${ }^{12,13,22,28-35}$

\section{Skin Atrophy}

Skin atrophy is considered to be one of the most important and most frequent side-effects of chronic topical GC treatment. The negative effects of GC can be seen in all skin compartments, which are characterized by severe hypoplasia, loss of elasticity with tearing and an increased fragility, telangiectasia, bruising, cutaneous transparency, or by a dysfunctional skin barrier. ${ }^{8,9,16,21,22,36}$ The catabolic nature of GC is an important part for this side effect, as GC determine protein degradation, enhance lipolysis, increases apoptosis, suppress inflammatory, immunologic and healing responses. ${ }^{25,37-39}$

The atrophogenic activity takes place earlier in the epidermis than in the dermal compartment. ${ }^{19}$

The process begins 3-14 days after GC treatment has started. The earliest degenerative changes are found in the epidermis, with reduction of cell dimensions and of cell layers. The basal layer is affected. The differentiation process is inhibited by suppressing cell proliferation and by accelerating keratinocyte maturation. It seems that epithelial stem cells found in the hair follicle are more affected in GC treatment and do not participate in regeneration after atrophy has been induced. ${ }^{12,21,40-43}$

The skin barrier function is affected in chronic topical GC use, becoming more permeable with basal transepidermal loss of water and electrolytes. The increased skin barrier permeability is associated with an attenuated stratum corneum, lipid content depletion and with lamellar body and intercellular lamellae decrease in numbers. ${ }^{12,21,40-44}$

Even the short term (3 days) topical administration of a potent GC has consequences on an epidermal level, affecting its structure and function. Although visible epidermal changes were absent, the stratum corneum registered a delay in recovery. Experimental mouse models and keratinocyte culture research showed a marked inhibition in epidermal lipid synthesis - ceramide, fatty acids and cholesterol. This could explain the barrier dysfunction through an impaired dual lipid layer in the stratum corneum, a decrease in lamellar body synthesis and secretion, but also through a decrease in the corneodesmosomes number (which result in a discohesive stratum corneum with increased permeability). ${ }^{12,21,27,29,44}$ The disturbance in skin barrier homeostasis is registered after the injured keratinocytes from the upper spinous layer start producing deteriorated lamellar bodies, with terminal differentiation into stratum corneum cells. ${ }^{21}$ The short-term treatment skin atrophy can be reversed, while the long-term one, which results in striae development is indeed permanent damage. $^{29}$

In short, topical GC affects stratum corneum components, subsequently affecting skin barrier integrity. ${ }^{12,21,44}$ The most affected class of lipids were ceramides, followed by triacylglycerols and unsaturated free fatty acids. ${ }^{21}$ The importance of the lipid component in the stratum corneum was proved by reestablishing skin permeability homeostasis after administering a topical treatment consisting of three essential stratum corneum lipids. Lipid synthesis in the stratum corneum is a key component of skin barrier homeostasis. $^{12,21,44}$

Ceramides are a major class of lipids, a result of terminal differentiation, which play a major role in skin barrier. They can be affected differently according to their chain-length. Long-chain ceramides that have an esterified omega-hydroxy-acyl chain register depleted levels in all species. Ceramides with 40 to $43 \mathrm{C}$ atoms in length, which are non-hydroxylated and those alpha-hydroxylated (which were more affected), presented lowered levels 
after topical GC treatment, while those with longer chains from the same class were not modified. Patients suffering from atopic dermatitis have significantly lower levels of ceramides in the stratum corneum, with a marked transepidermal loss of water. This is due to the decrease in the levels of long-chained esterified ceramides coupled with an increase in the short-chained ones - this is highly associated with an impaired skin barrier. Changes in the lipid profile of the skin in elderly patients have been observed, with decreases in transepidermal water loss. ${ }^{21}$

The dermis can also suffer from the negative effects of topical GC treatment. This is histologically evident and translates into dermal atrophy which is caused by directly inhibiting fibroblast proliferation. Mast cell numbers are reduced and the dermal support is lost; there is depletion of mucopolysaccharides (hyaluronic acid), elastin, matrix metalloproteases and collagen (especially collagen type I) synthesis. ${ }^{12,19,21,27,40,41,43}$ By regulating the activity of hyaluronan synthase-2, an enzyme involved in hyaluronic acid synthesis by keratinocytes and fibroblasts, GC can decrease the levels of hyaluronic acid which is important not only in maintaining the dermal and epidermal support, but also in skin flexibility and water-binding capacity. ${ }^{27}$ The elastin fiber compartment of the dermis is affected in different ways: the fibers from the superficial dermis become fragmented and thinned, and the ones found in the deep dermis are collapsed, forming a dense and closepacked network. The skin becomes thinned and brittle, with dilated blood vessels which present clinically as telangiectasia, purpura or striae, changes found frequently on the face. ${ }^{12,42,43}$

The atrophogenic effect can be observed also in hair follicles, sebaceous glands or dermal adipose tissue. ${ }^{23}$ Some studies reported that GC use induced not only atrophy of the epidermal and dermal compartments of the skin, but also that of the subcutaneous tissue (muscle fibers being also affected). ${ }^{29,41}$

Research using human skin cell cultures demonstrated that $\mathrm{GC}$ treatment can regulate extracellular matrix genes (fibronectin, collagen, various metalloproteinases) and can also influence the genes of lipid synthesis enzymes. ${ }^{21}$ Thus the capacity for skin remodeling is deeply affected, determining skin atrophy. ${ }^{27}$

The sexual dimorphism of topical GC use is a relatively new researched issue. As it is already known, sex steroid hormones are responsible for a different impact concerning skin physiology and pathology between men and women. Female patients suffer from skin thinning and dermal collagen loss after they have reached menopause, due to the lowering levels of estrogen. Also, females are more frequently affected by inflammatory skin disorders or by autoimmune ones, and men and women have a different response to inflammation. A preclinical study carried out by Baida et al in 2020 has shown that female mice are more susceptible to the atrophogenic effect of topical GC (due to a gene-inducing process, more specifically REDD1), even at lower doses, in comparison to male mice. Other genes are affected differently in regards to gender: Crtb1 is downregulated in females (and upregulated in males), while EGFR is upregulated in females (and downregulated in males), but as a result to systemic GC. The subject of topical GC sexual dimorphism remains an open one, more research being needed in this direction. $^{45,46}$

Another issue of growing concern is the topical GC withdrawal, as "steroid addiction" can lead to problems such as patient adherence to treatment and failure of prescribed treatment. There are 2 types of steroid withdrawal, morphologically distinct: the papulopustular one and the erythemato-edematous one, with overlapping signs and symptoms. The symptoms of withdrawal registered in patients with long-term treatment (approximately 12 months) are: erythema (most often; with the presence of the "headlight" sign), burning sensation, pain, pruritus, sun/heat exposure exacerbation, scaling or edema. The papulopustular variant of withdrawal differs from the second one by the prominent presence of papules, pustules and/or nodules, less frequently with edema or burning and stinging. ${ }^{47}$ There is a pattern of withdrawal concerning topical GC. Thus, at about a week after the treatment has been stopped, erythema develops in the area of the previous dermatitis, lasting for approximately two weeks and ending as a desquamation process. This first episode is frequently followed by a second flare in approximately two weeks. The cycle of erythemadesquamation-resolution repeats itself, with shorter duration of flares and longer resolution periods at each repeated cycle. The withdrawal phase lasts directly proportional to the period of time in which topical GC have been used. $^{35}$

A clear-cut management strategy for topical GC withdrawal has not yet been established; discontinuation of treatment and a supportive care (psychological support, cold packing/compresses) seem to be the only effective approaches. $^{47}$ 


\section{Skin Assessment \\ Dermoscopy}

The dermoscopy examination of the skin affected by the atrophogenic effects of $\mathrm{GC}$ reveals tortuous, irregularly dilated, tortuous, polygonal and interconnecting blood vessels (a consequence of the dermal support loss due to atrophy), white areas with no structure (a sign of dermal atrophy) and yellowish areas (a sign of epidermal atrophy with increased skin transparency). Inside the polygonal blood vessel network, some non-linear blood vessels can be found, along with small, red dots and terminal hairs. Some of these signs (such as telangiectasia or atrophy) can also be found in steroidinduced rosaceiform dermatitis, another consequence of the irrational or prolonged GC use. This investigation tool - dermoscopy - can be considered useful in the evaluation and follow-up of the GC negative effects on skin. ${ }^{48-50}$

\section{Integrated Multimodal Optical Microscopy}

This is a novel technique for skin assessment in which one can simultaneously acquire images by using: 1 ) two-photon excited fluorescence (TPEF) microscopy, 2) second harmonic generation microscopy (SHG), and 3) fluorescence lifetime imaging microscopy (FLIM). By combining these three microscopy techniques not only the structural characteristics of the skin can be evaluated, but also the cell metabolism, $\mathrm{pH}$, the local concentrations of oxygen and calcium, along with other biological parameters. This technique was used also in the study of cell death and wound-healing processes.

What the integrated multimodal optical microscopy technique revealed in the epidermis, was a higher rate of keratinocyte maturation, with fast corneocyte differentiation and shedding, the basal cells not being able to divide and replace the lost cells at an even pace. This can be explained through a metabolic shift from oxidative phosphorylation to glycolysis (a detection made by FLIM). Topical GC treated skin can be examined via this technique and changes can be identified even before they become clinically apparent. At a dermal level, the SHG imaging, along with the localized orientation index quantification, are important in the noninvasive revealing of the changes in structure and organization of collagen fibers which suffer remodeling. ${ }^{51}$

\section{GC and the Aging Skin}

Senile degenerative skin atrophy is a physiological phenomenon occurring in the elderly, sharing similarities with the skin atrophy found in topical GC use. ${ }^{52}$ Skin ageing changes have been evaluated with the help of classic techniques and newly developed ones, such as confocal laser scanning microscopy (CLSM). CLSM is a noninvasive and in vivo technique for skin evaluation which allows an "optical biopsy" to be made, revealing the morphological and dynamic changes of skin structures; it is ideal for real-time disease course monitoring and treatment response. It has been used in the study of various diseases such as lichen planus, plaque psoriasis, discoid lupus erythematosus, and even for wound healing or skin ageing. The changes that were found in skin ageing were epidermal keratinocyte alteration with irregular pigmentation and increasingly compacted dermal collagen fibers. ${ }^{53}$

As stated previously, the skin is capable of de novo steroid genesis from cholesterol and regulates the levels of local GC with the help of two enzymes (dehydrogenases). $11 \beta$-HSD1 converts cortisone (inactive form) to cortisol (active form). In the elderly, this enzyme is chronically elevated, possibly contributing to: GC-induced dermal and epidermal atrophy, dermo-epidermal junction flattening, decreased fibroblast proliferation and collagen content impairment in the dermis. ${ }^{54}$

The elderly seem to be even more negatively affected by GC use, both systemic and local, especially if they suffer from senile purpura or Bateman's purpura or dermatoporosis, which is a condition characterized by a chronic fragility of the skin that ages.

The clinical examination reveals a parchment, paperlike aspect of the translucent skin, with purple patches and whitish stellate pseudo-scars - this reflects an increased risk for tearing or poor wound healing. On histopathological examination, the skin affected by senile purpura has an attenuated epidermis with effaced rete ridges and an affected keratinocyte capacity for proliferation, while the dermis has a decreased volume.

The use of topical GC can aggravate or even induce Bateman's purpura, a major red flag for dermatologists when treating the elderly, since it can have severe consequences, even deep dissecting hematoma development. ${ }^{55,56}$

\section{Therapeutic Perspectives}

Mice model experiments used in preclinical studies found that the use of tretinoin, or tazarotene gel, or, respectively, rapamycin, were successful in preventing skin atrophy induced by GC treatment. ${ }^{17,41,44}$ Another preclinical study used topical and subcutaneous applications of a selective 11ß-HSD1 inhibitor which had promising results with increased epidermal keratinocytes, higher levels of dermal collagen and increased dermal thickness (possible due to an increased number in fibroblasts at this level) ${ }^{54}$ 
Another agent which has promising results in diminishing the early changes of topical GC activity (more specifically, betamethasone) act by modulating the extracellular matrix components - calcipotriol, a vitamin $D$ receptor agonist. It opposes the negative effects of GC on cell proliferation, the epidermal lipid profile and on antimicrobial peptides. It has beneficial effects on hyaluronic acid secretion which in turn acts both on the epidermal and dermal compartments. It determines keratinocyte proliferation, epidermal thickening, and, respectively, it induces collagen synthesis and increases matrix metalloproteinases expression. Metalloproteinase enhanced expression was different for matrix metalloproteinases 1 and 3 (MMP-1, MMP-3) - MMP-1 levels were augmented only in keratinocytes, while MMP-3 levels were increased both in keratinocytes and fibroblasts. ${ }^{27}$ Unfortunately, up until now, GC withdrawal seems to be the only effective measure that can be taken against the development of skin atrophy. ${ }^{19}$

Recent particularly important research has focused on the molecular mechanisms which underlie anti-inflammatory effects and atrophogenic ones; thus the concept of SEGRA emerges - Selective Glucocorticoid Receptor Agonists, a basis for newer GR ligands with potential for an improved therapeutic effects/side effects profile. In an attempt to separate the anti-inflammatory effects from the atrophogenic side effects, a preclinical study from 2020 by Dack et al researched the effects of LEO 134,310 as a selective and potent GR agonist, applied topically, with high potential for decreasing skin atrophy and a reduced systemic exposure, making it a possible agent for long-term use in dermatology (for skin diseases such as psoriasis, atopic dermatitis). ${ }^{57,58}$

Another possible treatment pathway with promising results is the targeted genes treatment, with negative gene regulation. FKBP51, a GR-dependent gene, and DDIT4/ REDD1 - regulated in development and DNA damage response 1 (a protein encoded by the DDIT4 gene), were found to act as atrophy promoters, and down-regulating or blocking them can determine at least a partial resistance to GC-induced atrophy. ${ }^{23,59}$

Targeted therapy by MR inactivation/blockade has promising results in topical GC-induced atrophy by having a partial effect on the cell proliferation inhibition of keratinocytes (reflected by a decreased Ki67 index). MR antagonists are a treatment possibility in such cases as topical spironolactone administration proved to be successful in a 2015 study by Maubec et al ${ }^{19,60}$.
Post-cortisone therapy corrective (non-first-line) measures could also include hyaluronic acid fillers (with reported patient satisfaction and no side-effects), ${ }^{61}$ the exact changes induced to the atrophic skin area being volume replacement by injection in the superficial and deep dermis, and the subcutaneous tissue, and also tissue regeneration with re-epithelization and increasing microvascular density. Dermal filling has already been used for decades in the treatment of various skin defects. ${ }^{62-64}$

Research on the curcumin effect on GC-treated atrophic mouse model skin revealed significant improvement, by gross and microscopic examination. Thus, the skin had a healthier aspect, with wound healing, regeneration (increased number of dermal fibroblasts with a much denser and organized appearance of collagen fibers) and triggered cell proliferation and differentiation of the epidermis and adnexal structures (especially the follicular bulge cells). This is possible due to biological activities exerted by curcumin such as antioxidant, anti-inflammatory or wound-healing. ${ }^{64-66}$

The tendency of the patient is to immediately cease topical GC treatment when negative side effects have been noticed, but this could have negative consequences such as - skin redness, an increased local temperature and burning sensation, the development of scales or pustules. ${ }^{49}$

\section{Conclusions}

$\mathrm{GC}$ are an essential part of dermatological treatment, being used in a various array of skin diseases with positive clinical results; thus being said, GC use (both current or prior use) is accompanied by many complications, some with permanent damage. Topical GC treatment has a major impact on stratum corneum lipids, which in turn influences the skin barrier integrity.

It is of the utmost importance to limit as much as possible the use of GC, and when that is not possible, to try and administer the lowest dosage with the highest benefit to adverse effects ratio and with the shortest duration Research is and should remain focused on GC treatment by developing methods of improving the risk to benefit ratio which characterize this class of drugs, by enhancing the efficacy of drug transportation to the exact sites of action and by developing newer, innovative targeted therapies.

\section{Abbreviations}

GC, glucocorticoids; BC, before cortisol; GR, the glucocorticoid receptor; MR, the mineralocorticoid receptor; DNA, deoxyribonucleic acid; $11 \beta$-HSD, $11 \beta$ - hydroxysteroid dehydrogenase; 11 $\beta$, hydroxysteroid dehydrogenase 1 - 
$11 \beta$-HSD-1; $11 \beta$, hydroxysteroid dehydrogenase $2-11 \beta$ HSD-2; TPEF, two-photon excited fluorescence microscopy; SHG, second harmonic generation microscopy; FLIM, fluorescence lifetime imaging microscopy; CLSM, confocal laser scanning microscopy; MMP-1, matrix metalloproteinase 1; MMP-3, matrix metalloproteinase 3; REDD1, regulated in development and DNA damage response 1; SEGRA, selective glucocorticoid receptor agonists.

\section{Author Contributions}

$\mathrm{EN}, \mathrm{CB}$, and ALT - made significant contributions to the conception, study design, acquisition, analysis and interpretation of data, and in writing this article; they have substantially revised and critically reviewed this article. All authors have agreed on the journal to which the article will be submitted and agree to take responsibility and be accountable for the contents of the article. All authors reviewed and agreed on all versions of the article before submission, during revision, the final version accepted for publication, and any significant changes introduced at the proofing stage.

\section{Funding}

No funding was received for this article.

\section{Disclosure}

The authors declare no competing interests.

\section{References}

1. Vandewalle J, Luypaert A, De Bosscher K, Libert C. Therapeutic mechanisms of glucocorticoids. Trends Endocrinol Metab. 2018;29 (1):42-54. doi:10.1016/j.tem.2017.10.010

2. Chung YS, Jin HL, Jeong KW. Cell-specific expression of ENAC $\alpha$ gene by FOXA1 in the glucocorticoid receptor pathway. Int J Immunopathol Pharmacol. 2020;34:2058738420946192. doi:10.1177/2058738420946192

3. Buttgereit F, Burmester GR, Lipworth BJ. Optimised glucocorticoid therapy: the sharpening of an old spear. Lancet. 2005;365 (9461):801-803. doi:10.1016/S0140-6736(05)17989-6

4. Cheah JTL, Robson JC, Black RJ, et al. The patient's perspective of the adverse effects of glucocorticoid use: a systematic review of quantitative and qualitative studies. From an OMERACT working group. Semin Arthritis Rheum. 2020;50(5):996-1005. doi:10.1016/j. semarthrit.2020.06.019

5. Christiansen JJ, Djurhuus CB, Gravholt CH, et al. Effects of cortisol on carbohydrate, lipid, and protein metabolism: studies of acute cortisol withdrawal in adrenocortical failure. J Clin Endocrinol Metab. 2007;92(9):3553-3559. doi:10.1210/jc.2007-0445

6. Peckett AJ, Wright DC, Riddell MC. The effects of glucocorticoids on adipose tissue lipid metabolism. Metabolism. 2011;60(11):1500-1510. doi:10.1016/j.metabol.2011.06.012

7. Kraft M, Soost S, Worm M. Chapter 95. Topical and systemic corticosteroids. In: John SM, Johansen JD, Rustemeyer T, Elsner P, Maibach HI, editors. Kanerva's Occupational Dermatology. 3rd ed. Switzerland: Springer Nature; 2020:1433-1439.
8. Deng J, Chalhoub NE, Sherwin CM, Li C, Brunner HI. Glucocorticoids pharmacology and their application in the treatment of childhood-onset systemic lupus erythematosus. Semin Arthritis Rheum. 2019;49(2):251-259. doi:10.1016/j.semarthrit.2019.03.010

9. Cain DW, Cidlowski JA. Specificity and sensitivity of glucocorticoid signaling in health and disease. Best Pract Res Clin Endocrinol Metab. 2015;29(4):545-556. doi:10.1016/j.beem.2015.04.007

10. Tatu AL, Nwabudike LC The treatment options of male genital lichen sclerosus et atrophicus. Short Title for a Running Head: treatments of genital lichen sclerosus. Proceedings of the 14th national congress of Urogynecology and the national conference of the Romanian Association for the Study of Pain; 2017 Sep 07-09; Eforie, Romania. 2017:262-264.

11. Tatu AL, Nwabudike LC. Male genital lichen sclerosus a permanent therapeutic challenge. J Am Acad Dermatol. 2018;79(3 Supplement 1):AB185.

12. Wiedersberg S, Leopold CS, Guy RH. Bioavailability and bioequivalence of topical glucocorticoids. Eur J Pharm Biopharm. 2008;68 (3):453-466. doi:10.1016/j.ejpb.2007.08.007

13. Coondoo A, Chattopadhyay C. Use and abuse of topical corticosteroids in children. Indian $J$ Paediatr Dermatol. 2014;15:1-4. doi:10.4103/2319-7250.131826

14. Vitellius G, Trabado S, Bouligand J, Delemer B, Lombès M. Pathophysiology of glucocorticoid signaling. Ann Endocrinol (Paris). 2018;79(3):98-106. doi:10.1016/j.ando.2018.03.001

15. Cole TJ. Glucocorticoid action and the development of selective glucocorticoid receptor ligands. Biotechnol Annu Rev. 2006;12:269-300.

16. Sainte Marie Y, Toulon A, Paus R, et al. Targeted skin overexpression of the mineralocorticoid receptor in mice causes epidermal atrophy, premature skin barrier formation, eye abnormalities, and alopecia. Am J Pathol. 2007;171(3):846-860. doi:10.2353/ajpath.2007.060991

17. Lesovaya E, Agarwal S, Readhead B, et al. Rapamycin modulates glucocorticoid receptor function, blocks atrophogene REDD1, and protects skin from steroid atrophy. J Invest Dermatol. 2018;138 (9):1935-1944. doi:10.1016/j.jid.2018.02.045

18. Nguyen VT, Farman N, Maubec E, et al. Re-epithelialization of pathological cutaneous wounds is improved by local mineralocorticoid receptor antagonism. $J$ Invest Dermatol. 2016;136 (10):2080-2089. doi:10.1016/j.jid.2016.05.101

19. Maubec E, Laouénan C, Deschamps L, et al. Topical mineralocorticoid receptor blockade limits glucocorticoid-induced epidermal atrophy in human skin. J Invest Dermatol. 2015;135(7):1781-1789. doi:10.1038/jid.2015.44

20. Sevilla LM, Pérez P. Roles of the glucocorticoid and mineralocorticoid receptors in skin pathophysiology. Int J Mol Sci. 2018;19 (7):1906. doi:10.3390/ijms19071906

21. Røpke MA, Alonso C, Jung S, et al. Effects of glucocorticoids on stratum corneum lipids and function in human skin - a detailed lipidomic analysis. J Dermatol Sci. 2017;88(3):330-338. doi:10.1016/j.jdermsci.2017.08.009

22. Agarwal S, Mirzoeva S, Readhead B, Dudley JT, Budunova I. PI3K inhibitors protect against glucocorticoid-induced skin atrophy. EBioMedicine. 2019;41:526-537. doi:10.1016/j.ebiom.2019.01.055

23. Baida G, Bhalla P, Yemelyanov A, et al. Deletion of the glucocorticoid receptor chaperone FKBP51 prevents glucocorticoid-induced skin atrophy. Oncotarget. 2018;9(78):34772-34783. doi:10.18632/ oncotarget.26194

24. Terao M, Katayama I. Local cortisol/corticosterone activation in skin physiology and pathology. J Dermatol Sci. 2016;84(1):11-16. doi:10.1016/j.jdermsci.2016.06.014

25. Slominski AT, Zmijewski MA. Glucocorticoids inhibit wound healing: novel mechanism of action. J Invest Dermatol. 2017;137 (5):1012-1014. doi:10.1016/j.jid.2017.01.024

26. Slominski AT, Brożyna AA, Tuckey RC. Cutaneous glucocorticoidogenesis and cortisol signaling are defective in psoriasis. $J$ Invest Dermatol. 2017;137(8):1609-1611. doi:10.1016/j.jid.2017.04.004 
27. Norsgaard H, Kurdykowski S, Descargues P, et al. Calcipotriol counteracts betamethasone-induced decrease in extracellular matrix components related to skin atrophy. Arch Dermatol Res. 2014;306 (8):719-729. doi:10.1007/s00403-014-1485-3

28. Seguro LP, Rosario C, Shoenfeld Y. Long-term complications of past glucocorticoid use. Autoimmun Rev. 2013;12(5):629-632. doi:10.1016/j.autrev.2012.12.002

29. Korting HC, Kerscher MJ, Schäfer-Korting M. Topical glucocorticoids with improved benefit/risk ratio: do they exist? $J$ Am Acad Dermatol. 1992;27(1):87-92. doi:10.1016/0190-9622(92)70162-9

30. Tatu AL, Ionescu MA, Clatici VG, Cristea VC. Bacillus cereus strain isolated from Demodex folliculorum in patients with topical steroid-induced rosaceiform facial dermatitis. An Bras Dermatol. 2016;91:676-678. doi:10.1590/abd1806-4841.20165214

31. Tatu AL, Ionescu MA, Nwabudike LC. Contact allergy to topical mometasone furoate confirmed by rechallenge and patch test. $A m$ J Ther. 2018;25(4):e497-e498. doi:10.1097/MJT.0000000000000581

32. Tatu AL, Ciobotaru OR, Miulescu M, et al. Hydrochlorothiazide: chemical structure, therapeutic, phototoxic and carcinogenetic effects in dermatology. REV CHIM (Bucharest). 2018;69(8):2110-2114. doi:10.37358/RC.18.8.6484

33. Nwabudike LC, Elisei AM, Buzia OD, Miulescu M, Tatu AL. Statins. A review on structural perspectives, adverse reactions and relations with non-melanoma skin cancer. REV CHIM (Bucharest). 2018;69 (9):2557-2562. doi:10.37358/RC.18.9.6575

34. Tatu AL, Elisei AM, Chioncel V, Miulescu M, Nwabudike LC. Immunologic adverse reactions of $\beta$-blockers and the skin (Review). Exp Ther Med. 2019;18(2):955-959. doi:10.3892/ etm.2019.7504

35. Abraham A, Roga G. Topical steroid-damaged skin. Indian J Dermatol. 2014;59(5):456-459. doi:10.4103/0019-5154.139872

36. DeFranco DB. Chaperoning skin atrophy. Oncotarget. 2018;9 (92):36407-36408. doi:10.18632/oncotarget.26375

37. Löfberg E, Gutierrez A, Wernerman J, et al. Effects of high doses of glucocorticoids on free amino acids, ribosomes and protein turnover in human muscle. Eur $J$ Clin Invest. 2002;32(5):345-353. doi:10.1046/j.1365-2362.2002.00993.x

38. Burt MG, Johannsson G, Umpleby AM, Chisholm DJ, Ho KKY. Impact of acute and chronic low-dose glucocorticoids on protein metabolism. J Clin Endocrinol Metab. 2007;92(10):3923-3929. doi:10.1210/jc.2007-0951

39. Hasan KM, Rahman MS, Arif KM, Sobhani ME. Psychological stress and aging: role of glucocorticoids (GCs). Age (Dordr). 2012;34(6):1421-1433. doi:10.1007/s11357-011-9319-0

40. Gauthier A, Fisch A, Seuwen K, et al. Glucocorticoid-loaded liposomes induce a pro-resolution phenotype in human primary macrophages to support chronic wound healing. Biomaterials. 2018;178:481-495. doi:10.1016/j.biomaterials.2018.04.006

41. Schwartz E, Mezick JA, Gendimenico GJ, Kligman LH. In vivo prevention of corticosteroid-induced skin atrophy by tretinoin in the hairless mouse is accompanied by modulation of collagen, glycosaminoglycans, and fibronectin. J Invest Dermatol. 1994;102 (2):241-246. doi:10.1111/1523-1747.ep12371770

42. Jung S, Lademann J, Darvin M, et al. Structural changes in human skin after topical application of glucocorticoids assessed by in vivo imaging technologies. $J$ Invest Dermatol. 2017;137(5):S46. doi:10.1016/j.jid.2017.02.288

43. Chebotaev DV, Yemelyanov AY, Lavker RM, Budunova IV. Epithelial cells in the hair follicle bulge do not contribute to epidermal regeneration after glucocorticoid-induced cutaneous atrophy. $J$ Invest Dermatol. 2007;127(12):2749-2758. doi:10.1038/sj. jid.5700992

44. Ahn SK, Bak HN, Park BD, et al. Effects of a multilamellar emulsion on glucocorticoid-induced epidermal atrophy and barrier impairment. $J$ Dermatol. 2006;33(2):80-90. doi:10.1111/j.13468138.2006.00018.x
45. Baida G, Agarwal S, Readhead B, Dudley JT, Budunova I. Sexual dimorphism in atrophic effects of topical glucocorticoids is driven by differential regulation of atrophogene REDD1 in male and female skin. Oncotarget. 2020;11(4):409-418. doi:10.18632/ oncotarget.27445

46. Quinn M, Ramamoorthy S, Cidlowski JA. Sexually dimorphic actions of glucocorticoids: beyond chromosomes and sex hormones. Ann Acad NY Sci. 2014;1317:1-6. doi:10.1111/nyas.12425

47. Hajar T, Leshem YA, Hanifin JM, et al. A systematic review of topical corticosteroid withdrawal ("steroid addiction") in patients with atopic dermatitis and other dermatoses. JAAD. 2015;72 (3):541-549. doi:10.1016/j.jaad.2014.11.024

48. Jakhar D, Kaur I. Dermoscopy of topical steroid damaged/dependent face. Indian Dermatol Online J. 2018;9(4):286-287. doi:10.4103/ idoj.IDOJ_301_17

49. Tatu AL. Topical steroid induced facial rosaceiform dermatitis. Acta Endo (Buc). 2016;12:232-233. doi:10.4183/aeb.2016.232

50. Tatu AL, Clătici V. Some correlations between the clinical and dermoscopic features of steroid induced facial dermatitis (abstract). J Am Acad Dermatol. 2015;72(5 Supplement 1):AB91.

51. Bower AJ, Arp Z, Zhao Y, et al. Longitudinal in vivo tracking of adverse effects following topical steroid treatment. Exp Dermatol. 2016;25(5):362-367. doi:10.1111/exd.12932

52. Schoepe S, Schäcke H, May E, Asadullah K. Glucocorticoid therapy-induced skin atrophy. Exp Dermatol. 2006;15(6):406-420. doi:10.1111/j.0906-6705.2006.00435.x

53. Ilie MA, Caruntu C, Lixandru D, et al. In vivo confocal laser scanning microscopy imaging of skin inflammation: clinical applications and research directions (Review). Exp Ther Med. 2019;17:1004-1011. doi:10.3892/etm.2018.6981

54. Boudon SM, Vuorinen A, Geotti-Bianchini P, et al. Novel 11ßhydroxysteroid dehydrogenase 1 inhibitors reduce cortisol levels in keratinocytes and improve dermal collagen content in human ex vivo skin after exposure to cortisone and UV. PLoS One. 2017;12(2): e0171079. doi:10.1371/journal.pone.0171079

55. Dyer JM, Miller RA. Chronic skin fragility of aging: current concepts in the pathogenesis, recognition, and management of dermatoporosis. $J$ Clin Aesthet Dermatol. 2018;11(1):13-18.

56. Fisher DA. Adverse effects of topical corticosteroid use. West J Med. 1995;162(2):123-126.

57. Schoepe S, Schäcke H, Asadullah K. Test systems for the determination of glucocorticoid receptor ligand induced skin atrophy. Dermatoendocrinol. 2011;3(3):175-179. doi:10.4161/derm.15065

58. Dack KN, Johnson PS, Henriksson K, et al. Topical 'dual-soft' glucocorticoid receptor agonist for dermatology. Bioorg Med Chem Lett. 2020;30(17):127402. doi:10.1016/j.bmcl.2020.127402

59. Klopot A, Baida G, Bhalla P, Haegeman G, Budunova I. Selective activator of the glucocorticoid receptor compound a dissociates therapeutic and atrophogenic effects of glucocorticoid receptor signaling in skin. $J$ Cancer Prev. 2015;20(4):250-259. doi:10.15430/ JCP.2015.20.4.250

60. Boix J, Nguyen VT, Farman N, Aractingi S, Pérez P. Mineralocorticoid receptor blockade improves glucocorticoid-induced skin atrophy but partially ameliorates anti-inflammatory actions in an irritative model in human skin explants. Exp Dermatol. 2018;27(2):185-187. doi:10.1111/exd.13473

61. Elliott L, Rashid RM, Colome M. Hyaluronic acid filler for steroid atrophy. J Cosmet Dermatol. 2010;9(3):253-255. doi:10.1111/j.14732165.2010.00508.x

62. Di Gregorio C, D'Arpa S. Therapeutic use of hyaluronic acid fillers in the treatment of corticosteroid-induced skin and subcutaneous atrophy. Dermatol Surg. 2016;42(11):1307-1310. doi:10.1097/ DSS.0000000000000810

63. Ardeleanu V, Dobre M, Georgescu EM. Deep facial wrinkle treatment outcome after first injection of reticulated hyaluronic acid. REV CHIM (Bucharest). 2015;66(12):2129-2131. 
64. Niculet E, Radaschin DS, Nastase F, et al. Influence of phytochemicals in induced psoriasis (Review). Exp Ther Med. 2020;20:3421-3424. doi:10.3892/etm.2020.9013

65. Niculet E, Neculia GV, Tatu AL, Buzia OD. Curcumin-extraction, physical and chemical analysis,formulas and control. Basic methods for further research. Mat Plast. 2018;55(4):672-675. doi:10.37358/ MP.18.4.5110
66. Fawzy S, Ahmed N, Eldin Elshafie M, Radwan S. Effect of curcumin versus hyaluronic acid on glucocorticoid induced skin atrophy and subsequent skin abrasions in rats. Egypt J Histol. 2019;42(1):35-50. doi:10.21608/ejh.2018.6166.1037

\section{Publish your work in this journal}

Clinical, Cosmetic and Investigational Dermatology is an international, peer-reviewed, open access, online journal that focuses on the latest clinical and experimental research in all aspects of skin disease and cosmetic interventions. This journal is indexed on CAS.
The manuscript management system is completely online and includes a very quick and fair peer-review system, which is all easy to use. Visit http://www.dovepress.com/testimonials.php to read real quotes from published authors. 